\title{
PENGARUH WAKTU TUNGGU PASIEN RAWAT JALAN TERHADAP KEPUASAN PELAYANAN PENDAFTARAN DI KLINIK X KOTA BANDUNG
}

\author{
Aulia Nurfadillah $^{1 *}$, Sali Setiatin ${ }^{2}$ \\ Politeknik Piksi Ganesha, Bandung ${ }^{1,2}$ \\ Piksi.aulia.18303218@gmail.com ${ }^{1}$, salisetiatin@gmail.com ${ }^{2}$
}

Received: $19-08-2021$

Revised : 19-09-2021

Accepted: 24-09-2021

\begin{abstract}
Abstrak
Latar Belakang : Waktu tunggu adalah waktu yang digunakan pasien untuk mendaftarkan pelayanan kesehatan mulai dari tempat pendaftaran sampai masuk ke ruang pemeriksaan dokter.waktu tunggu pasien merupakan salah satu komponen yang pontensial menyebabkan ketidak puasan pada pasien.
\end{abstract}

Tujuan : Penelitian ini bertujuan untuk mengetahui pengaruh waktu tunggu pasien rawat jalan terhadap kepuasan pelayanan pendaftaran di Klinik X Kota Bandung. Agar sesuai dengan SOP dan agar pelayanan kesehatan memberikan tingkat kepuasan terhadap pasien.

Metode Penelitian ini menggunakan rancangan kuantitatif statistik deskriptif. Responden berjumlah 25 pasien dengan menggunakan teknik sampel jenuh. Analisis dengan univariat dan uji chie square.

Hasil : Rata rata waktu tunggu pasien di Klinik X Kota Bandung selama 70 menit sebagian besar masih kategori lama $>60$ menit $(68.0 \%)$. tingkat kepuasan pelayanan pendaftaran dalam kategori kurang puas $(48,0 \%)$.

Kesimpulan : Rata-rata waktu tunggu pasien rawat jalan Klinik X Kota Bandung selama >60 menit $(68.0 \%)$ yaitu sekitar 70 menit masih dalam kategori lama. Tingkat kepuasan pelayanan pendaftaran yang diberikan Klinik $\mathrm{X}$ Kota Bandung masih dalam kategori kurang puas $(48,0 \%)$, dan pengaruh waktu tunggu pasien rawat jalan terhadap kepuasan pelayanan pendaftaran diperoleh nilai ( $\mathrm{p}$-value 0,004). Pasien akan merasa puas jika pelayanan yang diberikan sesuai harapan pasien atau bahkan lebih dari apa yang diharapkan pasien. Adanya pengaruh antara waktu tunggu pasien rawat jalan terhadap kepuasan pelayanan pendaftaran Klinik $\mathrm{X}$ Kota Bandung belum temasuk kedalam SOP (Standar Operasional Prosedur). Hal ini membuktikan bahwa dengan waktu tunggu pasien rawat jalan akan semakin meningkat atas rasa ketidakpuasan pelayan pendaftaran yang diberikan petugas.

Kata kunci: waktu tunggu; rawat jalan; kepuasan pasien; pelayanan pendaftaran. 


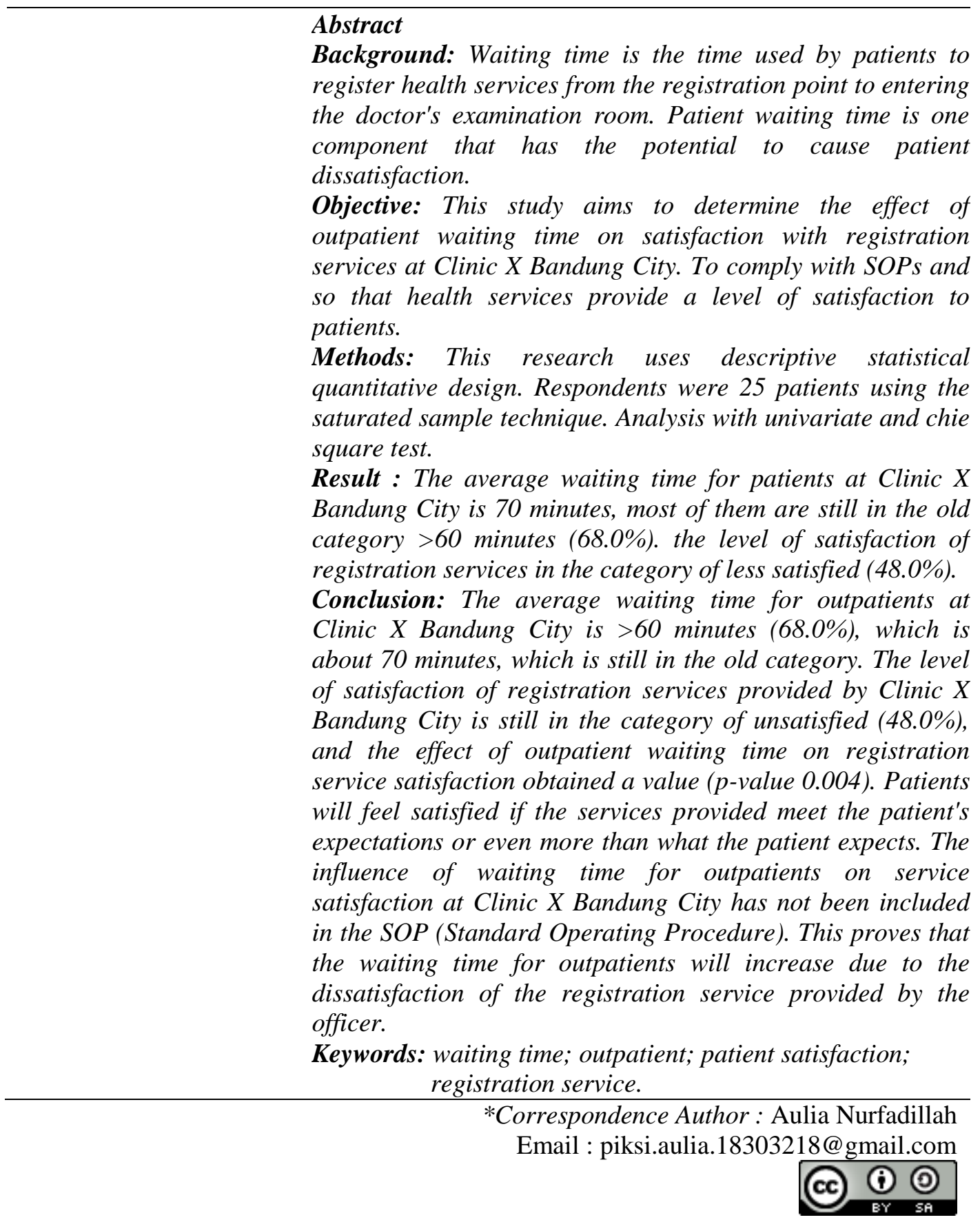

\section{PENDAHULUAN}

Klinik adalah fasilitas pelayanan kesehatan yang menyelenggarakan dan menyediakan pelayanan medis dasar dan spesialis, diselenggarakan oleh lebih dari satu jenis tenaga kesehatan dan dipimpin oleh satu seseorang tenaga medis (Depkes RI, 2014).

Pelayanan kesehatan merupakan faktor penting dalam meningkatkan derajat kesehatan dan kesejahteraan setiap orang, dan mempunyai hak dalam memperoleh pelayanan kesehatan dari pemerintah bertanggung jawab atas ketersediaan segala bentuk upaya kesehatan yang bermutu, aman, efisien, dan terjangkau oleh seluruh lapisan masyarakat ( $\underline{\mathrm{UU}}, 2009)$. 
Menurut (Bustani et al., 2015) Waktu tunggu adalah waktu yang digunakan pasien untuk mendapatkan pelayanan kesehatan mulai dari tempat pendaftaran sampai masuk ke ruang pemeriksaan dokter. Waktu tunggu pasien merupakan salah satu komponen yang potensial menyebabkan ketidakpuasan pada pasien. Menurut (Buhang, 2007), dikaitkan dengan manajemen mutu, aspek lama waktu tunggu pasien dalam mendapatkan pelayanan kesehatan merupakan salah satu hal penting dan sangat menentukan kualitas pelayanan kesehatan yang diberikan oleh suatu unit pelayanan kesehatan, sekaligus menceminkan bagaimana Klinik mengelola komponen pelayanan yang disesuaikan dengan situasi dan harapan pasien.

Pasien akan menganggap pelayanan kesehatan kurang baik apabila tidak mendapatkan pelayanan kesehatan yang tidak maksimal dan antrian lama, petugas kesehatan tidak ramah meskipun profesional. Bila waktu tunggu di pelayanan pendaftaran rawat jalan lama maka hal tersebut akan mengurangi kenyamanan pasien dan berpengaruh pada citra Klinik yang dapat mempengaruhi utilitas pasien dimasa mendatang (Hani, 2013).

Waktu tunggu di Indonesia ditetapkan oleh Kementrian Kesehatan (Kemenkes) melalui standar pelayanan minimal berdasarkan pada pelayanan rawat jalan indikator waktu tunggu pelayanan pasien rawat jalan yaitu 60 menit dimulai dari pasien mendaftar sampai dilayani oleh dokter (Kementerian Kesehatan Republik Indonesia, 2008).

Kepuasan adalah perasaan senang atau kecewa seseorang yang muncul setelah membandingkan antara persepsi atau kesannya terhadap kinerja atau hasil suatu produk dengan harapan-harapannya (Widayatun, 2009). Kepuasan pasien dapat membentuk persepsi dan selanjutnya dapat memposisikan produk perusahaan di mata pasiennya (Kusumaningtyas, 2016). Pasien yang tidak puas akan mencari pelayanan medis lain yang dapat memberikan nilai memuaskan.

Kepuasan pasien adalah respons evaluatif, afektif atau emosional yang terkait dengan mutu pelayanan yang diberikan rumah sakit serta harapan pasien terhadap pelayanan tersebut (Mumu et al., 2015). Kepuasan pasien akan terpenuhi apabila proses penyampaian jasa dari pembeli jasa kepada pasien sesuai dengan apa yang dipersepsikan pelanggan. Presepsi ini dipengaruhi oleh faktor subyektifitas yang dapat membuat perbedaan persepsi atau kesenjangan antara pelanggan dan pemberi jasa (Hafizurrachman, 2004).

Pendaftaran adalah tata cara penerimaan pasien yang akan berobat ke poliklinik maupun di rawat yang merupakan dari suatu sistem prosedur pelayanan Klinik. Dapat dikatakan bahwa disinilah pelayanan pertama kali di terima oleh seorang pasien mendapatkan kesan baik ataupun buruk dari suatu pelayanan klinik. Tata cara penerimaan pasien dapat dinilai baik dengan sikap ramah, sopan, tertib, dan penuh tanggung jawab (Yanmed, 2006).

Rekam medis adalah catatan atau dokumen tentang identitas pasien, pemeriksaan, pengobatan, tindakan dan pelayanan lain yang telah diberikan kepada pasien, setiap sarana kesehatan wajib membuat rekam medis. Berkas rekam medis dibuat oleh dokter atau tenaga kesehatan lain yang terkait, harus dibuat segera, dilengkapi setelah pasien menerima pelayanan, dan harus dibubuhi tandatangan yang memberikan pelayanan. (Permenkes RI, 2008).

Pelayanan rekam medis yang baik dan bermutu tercermin dari pelayanan yang ramah, cepat, serta nyaman. Pelayanan rekam medis rawat jalan dimulai dari tempat pendaftaran pasien sampai memperoleh dokumen rekam medis yang akan digunakan untuk mendapatkan pelayanan kesehatan. Bedasarkan standar penyedian dokumen rekam medis pelayanan rawat jalan adalah 10 menit, dan pelayanan dokumen rekam medis rawat inap 15 menit (Depkes, 2007). Maka pelayanan rekam medis di Klinik X Kota Bandung belum sesuai dengan standar pelayanan rekam medis menurut depkes 2007.

Bedasarkan penelitian observasi yang dilakukan pada tanggal 30 juni 2021 di Klinik X Kota Bandung menunjukkan bahwa waktu tunggu pasien rawat jalan di bagian 
pendaftaran melebihi SOP (Standar Operasional Prosedur) waktu tunggu pasien, dan terdapat berkas rekam medis yang tidak ditemukan oleh petugas dan menyebabkan pasien harus menunggu terlalu lama dalam mendapatkan pelayanan kesehatan. Oleh sebab itu, sering terjadinya ketidakpuasan waktu tunggu dalam pelayanan bagian pendaftaran kepada pasien. Hasil penelitian yang dilakukan menunjukkan dari 25 pasien responden menyatakan pelayanan waktu tunggu pasien selama pendaftaran memiliki waktu tunggu lebih dari 60 menit 68\%, dan tingkat kepuasan dalam kategori kurang puas 58,80\%. Jadi pengaruh waktu tunggu pasien terhadap kepuasan pelayanan pendaftaran belum sesuai dengan SOP (Standar Operasional Prosedur) pelayanan pendaftaran. Penelitian ini bertujuan untuk mengetahui pengaruh waktu tunggu pasien rawat jalan terhadap kepuasan pelayanan pendaftaran di Klinik X Kota Bandung. Agar sesuai dengan SOP dan agar pelayanan kesehatan memberikan tingkat kepuasan terhadap pasien.

\section{METODE PENELITIAN}

Metode penelitian ini menggunakan kuantitatif statistik deskriptif. Populasi dalam penelitian ini adalah sebagian pasien berjumlah 25 pasien responden. Responden penelitian ini mayoritas yang berumur 20-77 tahun Teknik yang digunakan adalah sampel jenuh adalah teknik menentukan sampel dimana semua anggota populasi digunakan menjadi sampel sehingga jumlah sampel penelitian sebanyak 25 pasien. Penelitian ini dilakukan di Klinik X Kota Bandung. Pengumpulan data ini menggunakan lembar kuesioner serta observasi, dan wawancara. Analisis data yaitu univariat dan uji chie square.

\section{HASIL DAN PEMBAHASAN}

\section{A. Hasil Penelitian}

Table 1. Frekuensi Waktu Tunggu Pasien Rawat Jalan di Klinik X Kota Bandung

\begin{tabular}{cccc}
\hline No & $\begin{array}{c}\text { Kategori Waktu Tunggu Pasien } \\
\text { Rawat Jalan }\end{array}$ & Jumlah (orang) & Persentase \\
\hline 1 & 60 menit & 8 & 32.0 \\
\hline 2 & $>60$ menit & 17 & 68.0 \\
\hline & Total & 25 & $100 \%$ \\
\hline
\end{tabular}

Berdasarkan tabel 1 menunjukkan bahwa dari 25 pasien responden diperoleh rata-rata waktu tunggu pasien lama rawat jalan Klinik X Kota Bandung $>60$ menit (kategori lama) dijumpai sebanyak 17 pasien lama rawat jalan $(68,0 \%)$.

Tabel 2. Frekuensi Berdasarkan Kepuasan Pelayanan Pendaftaran di Klinik X Kota Bandung

\begin{tabular}{cccc}
\hline No & Tingkat Kepuasan & Jumlah (orang) & Pesentase \\
\hline 1 & Sangat Puas & 7 & 28.0 \\
\hline 2 & Puas & 3 & 12.0 \\
\hline 3 & Cukup Puas & 3 & 12.0 \\
\hline 4 & Kurang Puas & 12 & 48.0 \\
\hline & Total & 25 & $100 \%$ \\
\hline
\end{tabular}


Berdasarkan tabel 2 menunjukan bahwa mayoritas responden memiliki tingkat kepuasan dalam kategori kurang puas sebanyak 12 pasien $(48,0 \%)$.

Table 3. Pengaruh Waktu Tunggu Pasien Rawat Jalan Terhadap Kepuasan Pelayanan Pendaftaran Di Klinik X Kota Bandung

\begin{tabular}{|c|c|c|c|c|c|c|c|c|c|c|c|}
\hline \multirow{3}{*}{$\begin{array}{c}\text { Waktu } \\
\text { Tunggu } \\
\text { Pasien } \\
\text { Rawat } \\
\text { Jalan }\end{array}$} & \multicolumn{10}{|c|}{ Kepuasan Pelayanan Pendaftaran } & \multirow[t]{3}{*}{ p-value } \\
\hline & \multicolumn{2}{|c|}{$\begin{array}{c}\text { Sangat } \\
\text { Puas }\end{array}$} & \multicolumn{2}{|r|}{ Puas } & \multicolumn{2}{|c|}{$\begin{array}{c}\text { Cukup } \\
\text { Puas }\end{array}$} & \multicolumn{2}{|c|}{$\begin{array}{c}\text { Kurang } \\
\text { Puas }\end{array}$} & \multicolumn{2}{|l|}{ Total } & \\
\hline & f & $\%$ & $\mathbf{f}$ & $\%$ & $\mathbf{F}$ & $\%$ & f & $\%$ & $\mathbf{f}$ & $\%$ & \\
\hline 60 Menit & 6 & $75 \%$ & 0 & 0 & 0 & 0 & 2 & $25,0 \%$ & 8 & $100 \%$ & \\
\hline$>60$ Menit & 1 & $5,90 \%$ & 3 & $17,60 \%$ & 3 & $17,60 \%$ & 10 & $58,80 \%$ & 17 & $100 \%$ & 0,004 \\
\hline
\end{tabular}

Berdasarkan tabel 3 menunjukkan dari 25 responden diketahui rata-rata waktu tunggu pasien $>60$ menit dengan kepuasan pelayanan pendaftaran kurang puas yaitu $58,80 \%$. Hasil uji chie square diperoleh nilai $p$-value 0,004 artinya alpha ( $\alpha=$ ditolak) yang berarti terdapat pengaruh yang signifikan antara Waktu Tunggu Pasien Rawat Jalan Terhadap Kepuasan Pelayanan Pendaftaran Di Klinik X Kota Bandung.

\section{B. Pembahasan}

Pelayanan rawat jalan memiliki indikator waktu tunggu pelayanan pasien rawat jalan yaitu 60 menit dimulai dari pasien mendaftar sampai dilayani oleh dokter. Kategori jarak antara waktu tunggu periksa yang diperkirakan bisa memuaskan atau kurang memuaskan pasien antara lain yaitu saat pasien datang mendaftar loket antri, dan menunggu panggilan poli umum untuk dianamnesis dan diperiksa dokter, perawat lebih dari 90 menit (kategori lama), 30-60 menit (kategori sedang), dan <30 menit (kategori cepat).

Hasil penelitian menunjukkan bahwa waktu tunggu pasien rawat jalan terhadap kepuasan pelayan pendaptaran Klinik X Kota Bandung 25 pasien responden diperoleh rata-rata waktu tunggu pasien rawat jalan selama 70 menit. Dihitung mulai dari pasien datang untuk mendaftar hingga pasien selesai berobat, dilihat dari table 1 Indikator waktu tunggu 60 menit (kategori sedang) dijumpai sebanyak 8 pasien $(32.0 \%)$ sedangkan waktu tunggu > 60 menit (kategori lama) dijumpai sebanyak 17 pasien (68.0\%). Dan dilihat dari table 2 tingkat kepuasan dalam kategori kurang puas 12 pasien (48.0\%). Dari hasil keseruhan pengaruh waktu tunggu pasien rawat jalan terhadap kepuasan pelayanan pendaftaran di klinik x kota bandung adalah $58,80 \%$.

Hasil tersebut menunjukkan bahwa waktu tunggu pasien rawat jalan di Klinik X Kota Bandung masih belum sesuai karena menurut pernyataan ( $\underline{\mathrm{RI}}, 2008)$ pada pelayanan rawat jalan indikator waktu tunggu pelayanan pasien rawat jalan yaitu 60 menit dimulai dari pasien mendaftar sampai dilayani oleh dokter. Sedangkan hasil yang diperoleh sebagian besar masih kurang dari pencapaian waktu tunggu yang dijadikan sebagai target, dan juga masih dalam kategori waktu lama, dimanana rata-rata waktu tunggu pasien rawat jalan yaitu selama 70 menit. Selama observasi ternyata lamanya waktu tunggu pasien rawat jalan disebabkan berkas rekam medis yang tidak ditemukan oleh petugas yang menyebkan pasien harus menunggu, dan antrian panjang oleh karena itu kebutuhan akan layanan melebihi kemampuan (kapasitas) pelayanan, sehingga pengguna fasilitas yang datang tidak bisa segera mendapatkan pelayanan kesehatan disebabkan kesibukan petugas pendaftaran.

Faktor lain yang mempengaruhi waktu tunggu pelayanan pendaftaran pasien di Klinik X bedasarkan hasil penelitian, didapatkan dari teknisi kinerja para petugas dalam memberikan pelayanan pendaftaran pasien rawat jalan, seperti kedisiplinan dalam 
memulai dan mengakhiri pelayanan kepada pasien rawat jalan, kurangnya rasa kerjasama yang terjalin antar para petugas dalam melaksanankan pelayanan rawat jalan (petugas rekam medis, petugas poliklinik, perawat, dokter) sekaligus kesadaran para petugas akan pentingnya waktu tunggu pelayanan pasien di rawat jalan. Untuk mengatasi masalah yang terjadi di Klinik X Kota Bandung, maka peneliti menyarankan agar pimpinan klinik dan kepala rekam medis perlu melakukan tindakan kedisisplinan kepada para petugas rekam medis, perawat dan juga dokter guna menigkatkan mutu pelayanan kepada pasien rawat jalan.

Sedangkan pelayanan rawat jalan rekam medis Klinik X Kota Bandung untuk 1 orang pasien membutuhkan waktu beberapa menit dan berdampak pada pasien hingga membuat pasien menunggu. Hasil dari rekam medis yang hilang atau belum ditemukan hingga membutuhkan waktu untuk mencari data rekam medis mempengaruhi waktu tunggu si pasien yang akan berobat rawat jalan dan dapat membuat pasien tidak puas atas pelayanan yang telah diberikan. Hubungan waktu tunggu dengan kepuasan pasien sangat nyata. Jika waktu tunggu terlalu lama pasien akan merasa tidak puas, sedangkan waktu tunggu yang singkat akan membuat pasien merasa puas sehingga pasien yang merasa puas akan memberi komentar baik tentang pelayanan kesehatan tersebut. (Fatrida \& Saputra, 2019)

Pelayanan pendaftaran Klinik dapat dikatakan bahwa disinilah pertama kali di terima oleh seorang pasien mendapatkan kesan baik ataupun buruk dari suatu pelayanan pendaftaran klinik. Tata cara penerimaan pasien oleh petugas dapat dinilai baik, dengan sikap ramah, sopan, tertib, dan penuh tanggung jawab atas pelayanan petugas yang disampaikan kepada pasien dan tanggapan seorang pasien tentang pelayanan petugas. Oleh karena itu mutu pelayanan pendaftaran menjadi pemicu bagi profesi kesehatan untuk meningkatkan pelayanan khususnya bagian pendaftaran dengan melalui kemampuan petugas dalam memberikan informasi, kecepatan dan ketetapan waktu pelayanan, ketetapan waktu pelayanan, ketanggapan dan keandalan. (Noviana, 2011)

Bedasarkan hasil penelitian menunjukkan bahwa hasil uji chie square diperoleh nilai p-value 0,004 yang berarti terdapat Pengaruh Waktu Tunggu Pasien Rawat Jalan Terhadap Kepuasan Pelayanan Pendaftaran di Klinik X Kota Bandung. Pada penelitian ini membuktikan bahwa Waktu Tunggu memiliki pengaruh yang signifikan. Artinya kepuasan pelayanan pendaftaran di Klinik X Kota Bandung sangat penting bagi para pasien.

\section{KESIMPULAN}

Bedasarkan hasil penelitian yang dilakukan pada saat di Klinik X Kota Bandung dapat disimpulkan bahwa rata-rata waktu tunggu pasien rawat jalan Klinik X Kota Bandung selama $>60$ menit $(68.0 \%)$ yaitu sekitar 70 menit masih dalam kategori lama. Tingkat kepuasan pelayanan pendaftaran yang diberikan Klinik X Kota Bandung masih dalam kategori kurang puas $58,80 \%$, dilihat dari penilaian pasien merupakan nilai subyektif pasien terhadap pelayanan pendaftran yang diberikan setelah membandingkan dari hasil pelayanan pendaftaran dengan harapannya. Pasien akan merasa puas jika pelayanan pendaftaran yang diberikan sesuai harapan pasien atau bahkan lebih dari apa yang diharapkan pasien.

Terdapat pengaruh antara waktu tunggu pasien rawat jalan terhadap kepuasan pelayanan pendaftaran di Klinik X Kota Bandung (p-value 0,004) belum temasuk kedalam SOP (Standar Operasional Prosedur) pelayanan kesehatan. Hal ini membuktikan bahwa dengan waktu tunggu pasien rawat jalan akan semakin meningkat atas rasa ketidakpuasan pelayan pendaftaran yang diberikan petugas. 
Menurut Kemenkes Nomor 129/menkes/SK/II/2008 menjelaskan standar pelayanan minimal waktu tunggu pelayanan pasien rawat jalan yaitu 60 menit dari pasien datang mendaftar sampai masuk ke ruang pemeriksaan dokter, jika lebih dari 90 menit (kategori lama), 30-60 menit (kategori sedang), dan <30 menit kategori cepat).

\section{BIBLIOGRAFI}

Buhang. (2007). Measuring Customer Satisfaction. PT. Gramedia Pustaka Umum. Jakarta.

Bustani, N. M., Rattu, A. J., \& Saerang, J. S. M. (2015). Analisis Lama Waktu Tunggu Pelayanan Pasien Rawat Jalan Di Balai Kesehatan Mata Masyarakat Propinsi Sulawesi Utara. Jurnal E-Biomedik, https://doi.org/10.35790/ebm.3.3.2015.10456

Depkes. (2007). Standar Pelayanan Minimal Rumah Sakit. Jakarta: Departemen Kesehatan RI.

Depkes RI. (2014). Peraturan Menteri Kesehatan Republik Indonesia Nomor 9 Tahun 2014 Tentang Klinik. Menteri Kesehatan Republik Indonesia Peraturan Menteri Kesehatan Republik Indonesia, Nomor 65(879), 2004-2006.

Fatrida, D., \& Saputra, A. (2019). Hubungan Waktu Tunggu Dengan Tingkat Kepuasan Pasien Dalam Mendapatkan Pelayanan Kesehatan. Jurnal 'Aisyiyah Medika, 4(1), 11-21. https://doi.org/10.36729/jam.v4i1.229

Hafizurrachman. (2004). Pengukuran Kepuasan Suatu Institusi Kesehatan. Majalah Kedokteran Indonesia, 54(7), 283-288.

Hani, F. D. (2013). Deskripsi Faktor-Faktor Yang Mempengaruhi Waktu Tunggu Pendaftaran di TPPRJ RSUD Tugurejo Semarang Tahun 2003. Journal of Chemical Information and Modeling, 53(9), 1689-1699.

Kementerian Kesehatan Republik Indonesia. (2008). 6 KMK No. 129 ttg Standar Pelayanan Minimal RS.pdf. In 129.

Kusumaningtyas, D. (2016). Pengaruh Kualitas Layanan Terhadap Kepuasan Pasien Rawat Inap Pada Rumah Sakit X Di Kota Malang. Jurnal NUSAMBA, 1(1), 68-76.

Mumu, L. J., Kandou, G. D., \& Doda, D. V. (2015). Analisis Faktor-Faktor Yang Berhubungan Dengan Kepuasan Pasien di Poliklinik Penyakit Dalam RSUP Prof . Dr . R . D . Kandou Manado Clinic of Internal Medicine Department of RSUP Prof . Dr . R . D . Kandou. Jurnal Unsrat, 1.

Noviana, H. . S. (2011). Hubungan Mutu Pelayan Pendaftaran dengan Kepuasan Pasien Rawat Jalan di Rumah Sakit PKU Muhammadiah Karanganyar. Jurnal Kesehatan, $V(1), 90-106$.

Permenkes RI. (2008). permenkes ri 269/MENKES/PER/III/2008. In Permenkes Ri No 269/Menkes/Per/Iii/2008 (Vol. 2008, p. 7).

RI, D. (2008). Keputusan Menteri Kesehatan Republik Indoneia Nomor. 129 Tahun 2009 Tentang Standar Pelayanan Minimal Rumah Sakit. Jakarta: Kemenkes RI.

UU. (2009). Undang-Undang Republik Indonesia Nomor 36 Tentang Kesehatan. Jakarta, $2(5), 255$.

Widayatun. (2009). Ilmu Prilaku. Jakrta: Info Medika.

Yanmed, D. (2006). Pedoman pengelolaan rekam medis di rumah sakit di indonesia. Jakarta: Depkes R.

(C) 2021 by the authors. Submitted for possible open access publication under the

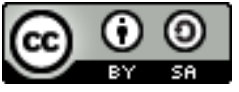
terms and conditions of the Creative Commons Attribution (CC BY SA)

license (https://creativecommons.org/licenses/by-sa/4.0/). 